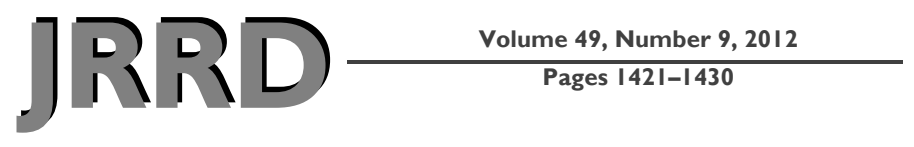

\title{
In vivo trial results of a novel ultrasonic cough stimulator
}

\author{
Jennifer C. Nitz, PhD, MPhty, BPhty; ${ }^{1^{*}}$ John Perrier, BPhty; $^{1-2}$ Peter Cook, MBBS, FANZCA, FCICM ${ }^{3}$ \\ ${ }^{1}$ Division of Physiotherapy, School of Health \& Rehabilitation Sciences, The University of Queensland, St. Lucia, \\ Australia; ${ }^{2}$ Medivations, Brisbane, Australia; ${ }^{3}$ Adult Critical Care Services, Mater Hospital, Brisbane, Australia
}

\begin{abstract}
The aims of these double-blind in-vivo trials of a prototype ultrasonic cough stimulator (CoughStim ${ }^{\mathrm{TM}}$ ) were to establish (1) whether ultrasound (US) stimulation can be safely used to stimulate a cough, (2) the most efficient US frequency and power parameters to reliably stimulate a cough, (3) whether single- or dual-sided stimulation is more effective, and (4) whether a cough can be stimulated in adults unable to cough on demand. Fifteen nondisabled volunteers (18-59 yr) and seven volunteers unable to cough on demand (85-102 yr) were recruited. Stimulation was applied to the neck unilaterally at eight frequencies and two power levels and bilaterally at two frequencies and three power levels. Vital signs were monitored during testing with no adverse responses. CoughStim stimulated a cough in all nondisabled subjects, $80 \%$ of subjects at $0.58 \mathrm{MHz}$ and $9 \mathrm{~W}$ unilaterally and $75 \%$ of subjects at $0.58 \mathrm{MHz}$ and $6 \mathrm{~W}$ bilaterally. Of the subjects unable to cough, 71 percent responded to bilateral stimuli $(0.54 \mathrm{MHz}$ and $6 \mathrm{~W})$ with a strong cough. The CoughStim regularly and safely produced a moderately strong cough response in subjects with or without ability to cough and produced this effect without causing undue discomfort.
\end{abstract}

Key words: clinical trial, cough response, CoughStim ${ }^{\mathrm{TM}}$, cough stimulation, cough strength, in vivo, noninvasive, prototype, secretion removal, ultrasound.

\section{INTRODUCTION}

Clearing accumulated secretions from the airways is usually achieved by coughing [1-2]. Coughing is an accepted part of treatment for respiratory conditions where secretion removal is important, such as pneumonia, chest infection, or atelectasis [1]. There are a number of clinical situations in which the ability to cough voluntarily is absent or diminished, which may predispose the patient to or prolong the effects of respiratory diseases [1]. For example, the patient may be in a vegetative or obtunded state due to comorbidity of an incapacitating illness, be sedated, or have altered consciousness due to medication and/or anesthetic [1]. Another reason that the ability to cough on demand may be diminished is pain inhibition, e.g., after rib fracture or thoracic and/or abdominal surgery [2]. Neurological conditions such as dysphasia or dyspraxia may also render a person unable to cough when there is an inability to understand and execute the demand to cough voluntarily [1]. Cough reflexes might be absent or inhibited in patients with acquired brain injury when dysphagia is a presenting symptom [3]. Other examples include those with traumatic brain injury, dementia [1], and even those who are too young to comprehend an instruction, e.g., a neonate with cystic fibrosis [4]. Aspiration pneumonia due to lack of spontaneous cough in response to airway irritation is a further consequence of poor airway protection [2,5]. In these cases and more, the inability to cough on demand

\footnotetext{
Abbreviations: $\mathrm{PEFR}=$ peak expiratory flow rate, $\mathrm{QB}=$ quiet breathing, $\mathrm{SpO}_{2}=$ partial pressure of oxygen, $\mathrm{T}=$ thoracic, $\mathrm{US}=$ ultrasound.

*Address all correspondence to Jennifer C. Nitz, PhD, MPhty, BPhty; Division of Physiotherapy, School of Health \& Rehabilitation Sciences, The University of Queensland, St. Lucia, 4072, Australia; +61-7-3365-2791; fax: +61-7-33651622. Email: j.nitz@uq.edu.au

http://dx.doi.org/10.1682/JRRD.2011.07.0121
} 
can predispose the patient to respiratory complications or retard treatment, adversely affecting patient outcomes.

Clinical removal of lung secretions in patients who are unable to cough when instructed can be difficult and invasive; it often requires the use of tracheal suction. Therapeutic bronchoscopy is also used to this end [6]. These interventions are uncomfortable and can be distressing for patients. Furthermore, repeated suction over a period of greater than 3 to $4 \mathrm{~d}$ may require the insertion of a nasotracheal or endotracheal airway to minimize airway trauma. In turn, this airway can cause insult if left in situ for longer than 2 wk [7], necessitating surgical minitracheotomy to facilitate further suction [8]. All of these interventions have associated side effects and risks. Therefore, a noninvasive and comfortable method of stimulating a cough that is effective in assisting removal of secretions from the airways would be welcome.

The cough reflex is an important defense mechanism for the respiratory tract. Each cough begins with the stimulation of the sensory nerve endings that function as cough receptors [2]. These are found in the upper and lower respiratory tract [9], specifically in the larynx, trachea, and bronchial mucosa [10]. Afferent stimulation that induces a cough in patients with upper respiratory tract or lung pathology is via mucosal irritation from sputum or mucosal inflammation $[1,11]$. Investigation of the cough reflex or assistance with airway clearance for patients with retained secretions has been achieved using artificial methods such as inhaling irritants [12], mechanically stimulating the mucosa by inserting a suction catheter [6,11], high-frequency chest wall percussion [13], externally applied mechanical vibrator [11], or electrical stimulation of the tracheal mucosa [14]. All of these methods, except high-frequency chest wall percussion and mechanical vibration stimulation of the neck in the region of the suprasternal notch, are invasive to the patient.

Anatomical studies have indicated that the middle ramus of the internal branches of the superior laryngeal nerve supplies the mucosa of the vestibule of the larynx and specifically the quadrangular membrane most likely conveys the afferent stimulus for the cough reflex [15]. Therefore, stimulating this area of the larynx to obtain a cough reflex is most appropriate. To that end, a new apparatus, the CoughStim ${ }^{\mathrm{TM}}$ cough stimulator (formerly known as the RESUSS-C device, Medivations; Brisbane, Australia), was developed. The CoughStim delivers an ultrasound (US) stimulus that is applied externally to the skin overlying the larynx. The ultrasonic vibrations pene- trate into the larynx, whereupon they excite the irritant receptors in the laryngeal wall and rapidly adapting receptors in the tracheobronchial mucosa [16], stimulating a reflex cough in the patient.

US at a frequency of $1.0 \mathrm{MHz}$ is commonly utilized during treatment application for soft tissue injury, e.g., by physiotherapists [17]. The frequency of ultrasonic waves and the power output determine the depth of tissue penetration. There are physical properties of sound, namely refraction and reflection, that also affect the passage of US through tissues of various densities. The parameters and application method inherent to the CoughStim we examined during this investigation are similar to those currently used in the clinical percutaneous application of US to other sites of the body by physiotherapists.

The aim of this series of studies was to undertake controlled in vivo testing of the prototype CoughStim device. Study 1 determined the reliability of US in stimulating a cough in nondisabled adults, determined the most efficient frequency and power parameters of US to stimulate the cough, and established whether the cough stimulation was safe and tolerable to the subject. Study 2 determined whether single- or dual-sided stimulation was more effective in stimulating a cough. Studies 3 and 4 validated the results from studies 1 and 2 and determined whether the US stimulation could elicit a cough in adults "unable to cough" on demand and demonstrated that stimulated cough strength was sufficient to remove secretions.

\section{METHODS}

\section{Subjects}

We conducted studies 1 and 2 at the same time using the same group of subjects. Subjects included 15 nondisabled adults ( 8 female and 7 male) able to provide informed written consent and aged between 18 and $59 \mathrm{yr}$ (mean: $32.3 \mathrm{yr}$ ). They had volunteered from the community in response to advertisements on university notice boards and local newspapers. We excluded volunteers if they had any neuromusculoskeletal conditions that would affect the ability to cough, e.g., spinal cord injury, acquired brain injury, muscular dystrophy, or respiratory disease such as asthma or hay fever. We also excluded subjects if they had experienced a recent upper respiratory tract infection because this has been shown to increase the sensitivity to mechanical stimulation of the cough reflex [11]. 
Study 3 comprised seven older subjects (6 female and 1 male) who were unable to cough on demand due to their medical conditions, including dementia and stroke, rendering them unable to obey verbal commands. We recruited them from an aged care facility in the Brisbane, Australia, area. The age of these participants ranged from 85 to 102 yr (mean: 92.4 yr). We obtained informed consent to participate from their legal guardians.

Study 4 included five nondisabled subjects ( 2 female and 3 male) aged from 19 to 44 (mean: 38.2 yr) who had not participated in studies 1 or 2 . The subjects complied with the same inclusion and exclusion criteria as for studies 1 and 2 .

\section{Study Design}

These studies were designed to test and validate the CoughStim prototype (Figure 1). We used a doubleblinded intervention trial where the subjects and the investigator applying the US stimulus did not know the US parameter settings.

We included study 4 as a post-hoc study to validate the cough strength response to stimulation. The aim was to show that peak expiratory flow rate (PEFR) of a cough stimulated by the most effective US frequency and power demonstrated in the previous studies achieved an expiratory flow rate greater than the 160 to $270 \mathrm{~L} / \mathrm{min}$ previously shown to be needed to clear secretions [18].

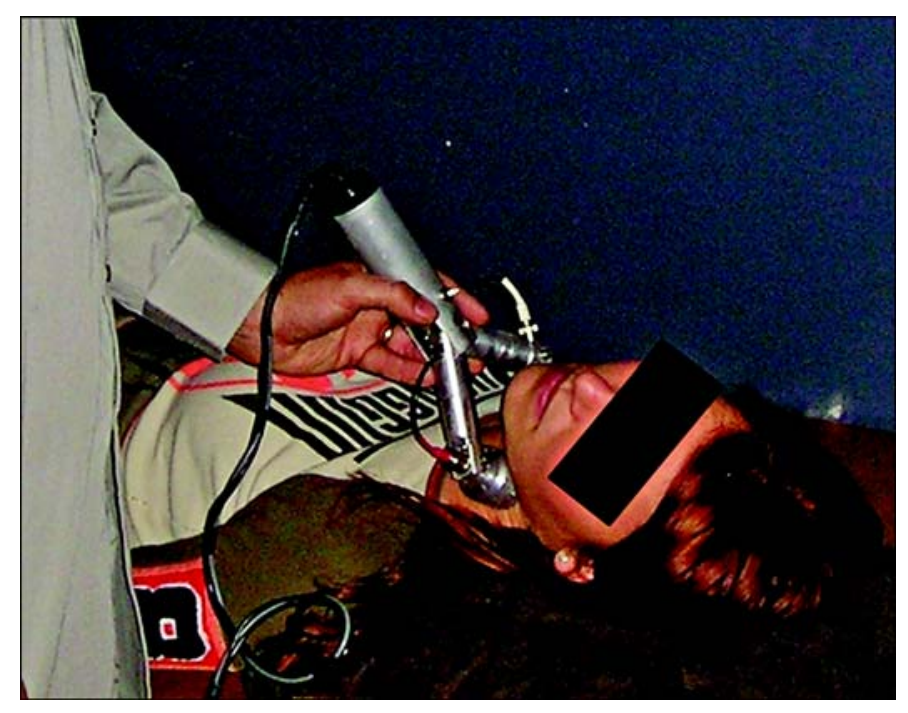

Figure 1.

Application of CoughStim ${ }^{\mathrm{TM}}$ (Medivations; Brisbane, Australia) using bilateral ultrasound heads.

\section{Measurements}

Cough

The cough process consists of an inspiratory phase, compressive phase, and expiratory phase [19]. Therefore, the volume of air shifted in the expiratory phase will determine the size of the cough effort. Furthermore, chest excursion is quicker in a cough than in normal breathing. A simple noninvasive indicator of these thoracic movements can be obtained using Respitrace (respiratory induction plethysmography). This equipment consists of a load cell that measures the changes in pressure that occur with change in volume of the thorax as indicated by chest expansion [20]. We positioned the Respitrace around the chest at the thoracic (T) T12 level.

Dekens et al. qualitatively graded cough as none, weak, normal, and strong [14]. We have graded the cough from 0 to 4 , where $0=$ no response; 1 = a simple throat clearing maneuver in response to US irritation; and weak, normal, and strong coughs are 2, 3, and 4, respectively. Recording the Respitrace measure of the thoracic expansion provided quantitative support for accepting the qualitative scoring of the cough response. Figure 2 shows the change in the Respitrace recording between quiet breathing (QB) and a normal cough response obtained from a nondisabled subject. We used the average displacement during QB as a baseline against which we measured the cough volume that was stimulated by the US stimulus. We compared the maximum slope of the curve, denoting the rate of change of the chest wall movement during the cough, with the maximum slope of the curve recorded during forced expiration maneuver of the peak expiratory flow effort (we instructed patients, using a Wright peak flow meter [Armstrong Medical Industries Inc; Lincolnshire, Illinois], to "blow out as hard and fast as you can until all your air is gone”).

For study 4, we compared the PEFR during a voluntary maximum cough with that achieved when using the most effective cough stimulating parameters determined in the previous studies. We used a portable peak flow meter to gather these data. This method of measuring cough has been shown to be reproducible and accurate when flows are $>270 \mathrm{~L} / \mathrm{min}$ [18], as expected in the nondisabled subjects included here.

Perceived sensation during application of the US stimulus was important to measure because application comfort was a high priority when designing the CoughStim 


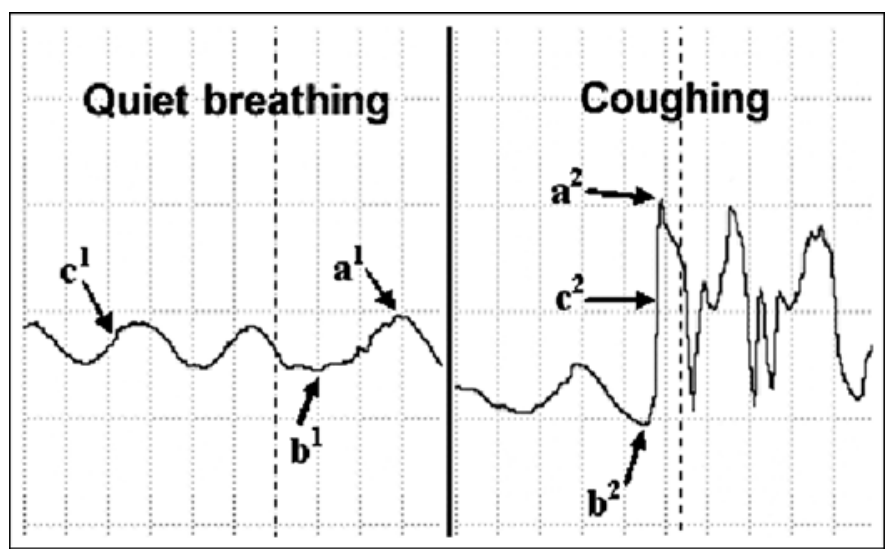

Figure 2.

Sample of Respitrace (respiratory induction plethysmography) curves illustrating difference between quiet breathing (QB) and coughing. Displacement of curve represents thoracic excursion of subject. Displacement is less during $Q B\left(a^{1}-b^{1}\right)$ than during coughing $\left(a^{2}-b^{2}\right)$. Chest wall movement, and therefore depth of respiration, was greater during coughing than QB. Similarly, slope of Respitrace curve indicates rate of change of thoracic movement. Hence, steepest part of curve (estimated at $c^{1}$ and $c^{2}$ ) indicates period of most rapid chest wall movement. Due to powerful forced expiration involved in coughing maneuver, maximum slope of curve is far greater during coughing $\left(c^{2}\right)$ than during QB $\left(\mathrm{c}^{1}\right)$.

prototype. We used a 5-point Likert scale of sensation descriptors, where $0=$ no sensation, $1=$ slight, $2=$ mild, 3 = moderate, $4=$ strong, and $5=$ unbearable. A 5-point Likert scale has been shown to be as accurate as a visual analog scale with 2 anchor points or Borg scale with 12 fixed points when measuring a perceived effect [21].

\section{Vital Signs}

A possible undesirable side effect of US stimulation applied over the larynx is laryngeal spasm. To check for signs of such spasm, we performed a PEFR test at baseline and between each cough stimulus event. There might also have been a vagus nerve stimulation response resulting in altered heart rate or blood pressure. We monitored these vital signs, as well as partial pressure of oxygen $\left(\mathrm{SpO}_{2}\right)$ and respiratory rate, during and between stimuli for all subjects. We questioned all subjects regarding any lingering laryngeal irritation after each application and made a follow-up telephone call the day following the procedure to determine whether the subjects had experienced any latent symptoms of laryngeal irritation or inflammation. These questions, along with the PEFR, were applied to nondisabled subjects only because the older subject group was unable to perform them adequately. If we noted any adverse response, the intervention would be stopped and the subject rested with vital signs monitored until they returned to preintervention levels and remained stable.

Predetermined indicators of adverse response for cessation of intervention included signs of laryngeal spasm, reduction in forced expiratory volume $>25$ percent of pretest measurement, cardiac rhythm change \pm 25 percent of resting rate, change in respiratory rate $>20$ breaths/min or $<5$ breaths/min, or $\mathrm{SpO}_{2}<90$ percent. As a precaution against any physiological adverse reaction, we conducted the first phase of testing involving nondisabled subjects in the intensive care unit at Mater Hospital (Brisbane, Australia) with an intensivist in attendance.

\section{Procedure}

We positioned each subject in a reclined sitting position on a bed with the head supported on pillows and a pillow under the knees to relax the abdominal muscles. We secured the Respitrace around the chest at the T12 level and connected it to a laptop computer data recorder for continual monitoring of chest movement during all conditions measured. We secured the blood pressure cuff around the upper left arm and placed the oximeter probe on the right index finger.

We measured PEFR using a Wright peak flow meter before testing each condition of the US application and again 2 min after stimulation and the cough response ceased. These measurements were continued every $15 \mathrm{~min}$ for $1 \mathrm{~h}$ after the final test condition was completed to ensure that we identified any delayed adverse response that might have occurred.

We tested the conditions of US stimulation in random order (computer generated). The subject and the investigator applying the CoughStim were blinded to stimulation order. These were changed between each stimulus condition by an assistant investigator who followed a predetermined random order that was different for each participant. The assistant also monitored the vital signs.

We applied US stimuli to the larynx in nondisabled subjects unilaterally at eight frequencies $(0.54,0.58$, $0.61,0.74,0.87,0.98,1.18$, and $1.35 \mathrm{MHz}$ ) and two power levels ( 6 and $9 \mathrm{~W}$ ) and bilaterally at $0.58 \mathrm{MHz}$ and 4 and $6 \mathrm{~W}$. We repeated application of the stimuli in four 
of the nondisabled subjects to determine stability of testretest results.

We chose the stimulation parameters found to be most comfortable and effective in stimulating a cough for nondisabled subjects to test in study 3 on subjects who were unable to cough. Modification of the equipment after completion of the nondisabled subject trials enabled bilateral stimulation at $0.54 \mathrm{MHz}$. Subjects in the unable to cough group were stimulated unilaterally at $0.54,0.58$, 0.61 , and $0.74 \mathrm{MHz}$ and 0,6 , and $9 \mathrm{~W}$ and bilaterally at 0.54 and $0.58 \mathrm{MHz}$ and 0 and $6 \mathrm{~W}$. We included a placebo application of $0 \mathrm{~W}$ to determine whether the touch of the sound head on the neck stimulated a cough. This would enable this aspect of stimulation to be considered in interpretation of results should a cough be elicited.

Between each frequency condition and each unilateral or bilateral application, the subject rested so the investigators could be sure all the measurements and vital signs being monitored returned to prestimulation levels.

For the cough strength validation study, we positioned subjects as for the earlier studies. As previously, we applied a US stimulus using bilateral stimulation at $0.54 \mathrm{MHz}$ and $6 \mathrm{~W}$. We chose these parameters considering nondisabled and unable to cough subjects' results from studies 1 to 3. Prior to stimulation, five nondisabled subjects produced a maximum voluntary cough while PEFR was recorded with the portable peak flow meter. We measured PEFR the same way for coughs stimulated by the CoughStim. We also recorded the strength of the cough response.

\section{Analysis}

We used descriptive statistics to present the results. The proportion of the subjects exhibiting a cough response is reported for nondisabled and unable to cough subjects. We did not include cough strengths of 1 in the count because they did not represent a clinically adequate cough. Responses are reported to show comparison of stimulus parameters of frequency and power during unilateral stimulation and for bilateral stimulation at one frequency and two power levels. Perceived sensation is also reported. A quantitative confirmation of cough strength is provided by two sets of data. First, we report the maximum displacement of the Respitrace curve, which we then compared with the maximum displacement during QB; these data give a semiquantitative representation of the depth of the cough via the total thoracic excursion. Second, we report the maximum slope of the curve dur- ing the cough effort, which we then compared with the maximum slope during the PEFR maneuver, giving an indication of the power of the cough via the speed of the chest wall movement.

We graphically presented raw data from study 4 compared with the minimum expiratory flow rates for an effective cough. We also noted subjective cough strength. Using SPSS version 17 (IBM Corporation; Armonk, New York), we applied a paired $t$-test to determine difference in PEFR between voluntary and stimulated cough.

\section{RESULTS}

We monitored vital signs for all nondisabled and unable to cough subjects during testing and recorded no adverse responses. Table 1 shows the baseline results and the effect of stimuli, including the average duration of US stimulus until a cough was elicited.

\section{Nondisabled Subject Group}

The proportion of nondisabled subjects with a cough response to at least one stimulation was 100 percent. US at $0.58 \mathrm{MHz}$ and $9 \mathrm{~W}$ stimulated a cough in 80 percent of nondisabled participants (12 of 15 subjects). The strongest coughs were stimulated at $0.54 \mathrm{MHz}$ and $0.58 \mathrm{MHz}$ and $9 \mathrm{~W}$ with a mild to moderate sensory level at the higher frequency. A cough was stimulated within an average of 2.9 s (range: $0.1-5.5 \mathrm{~s}$ ) from commencement of stimulation at $0.58 \mathrm{MHz}$ and $9 \mathrm{~W}$. A stimulation of $0.54 \mathrm{MHz}$ and $9 \mathrm{~W}$ elicited a cough in 73 percent of subjects (11 of 15 subjects) (Table 1). We performed bilateral stimulation using paired power heads at $0.58 \mathrm{MHz}$ and two power levels, 4 and $6 \mathrm{~W}$, on 12 nondisabled subjects. We stimulated a cough in 75 percent (9 of 12) nondisabled subjects at $6 \mathrm{~W}$ compared with 40 percent with singlesided stimulation at this parameter setting (Table 1). Cough strength was a grade of 3 for a power level of $6 \mathrm{~W}$ and 2 for $4 \mathrm{~W}$, while sensation was 2.50 at $6 \mathrm{~W}$ and 1.85 at $4 \mathrm{~W}$.

We confirmed the subjective data by thoracic expansion as measured by the Respitrace. These curves showed a greater displacement during coughing than during QB. Furthermore, the maximum slope of the curve during coughing is reported and compared with the maximum slope of the curve during the PEFR maneuver. Table 2 shows these data for the nondisabled subject group. We stimulated the strongest average cough using unilateral 
JRRD, Volume 49, Number 9, 2012

Table 1.

Mean \pm standard deviation values for vital signs, percentage cough response, and duration of stimulus until cough response.

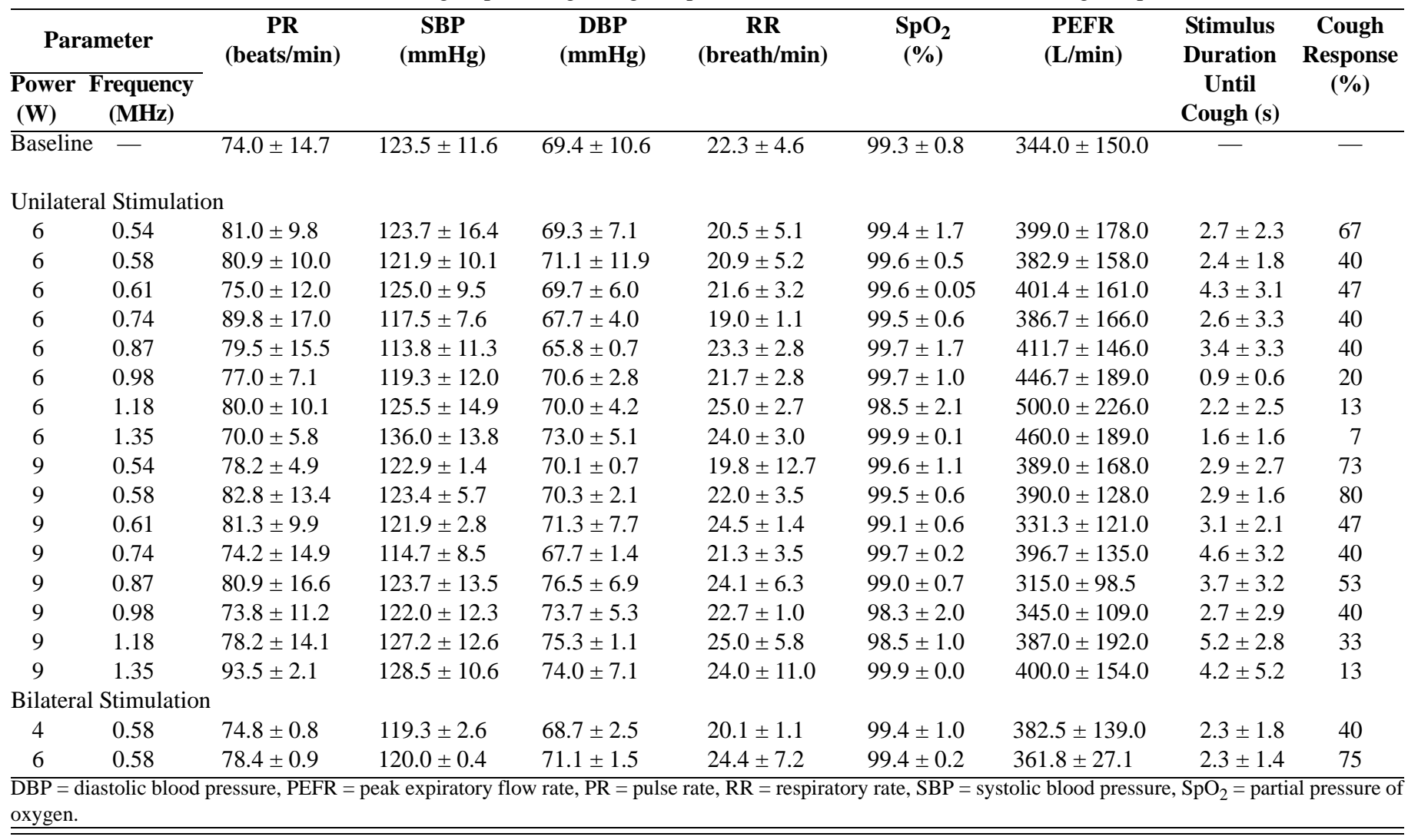

stimulation at a frequency of $0.58 \mathrm{MHz}$ and $9 \mathrm{~W}$ with 80 percent of responses $\geq 2$ cough strength, 179.7 percent greater displacement of the curve than during QB, and the slope of the Respitrace curve being 106.8 percent of the PEFR effort slope. Bilateral stimulation at $0.58 \mathrm{MHz}$ and $6 \mathrm{~W}$ was also very effective, producing an effective cough in 75 percent of subjects with an average thoracic expansion displacement of nearly double QB and a slope 89.9 percent as steep as the PEFR curve.

\section{Unable to Cough Subject Group}

We never generated a cough with the placebo application of $0 \mathrm{~W}$ for the unable to cough subjects. Two subjects in the group never responded to stimulation, unlike the nondisabled subjects who all responded to some stimulus parameters. Unilateral stimulation elicited a cough in four of the seven subjects, although there was less consistency of frequency or power stimulus to gain these responses. Of the participants in the group, 71 percent had a cough response when stimulated bilaterally at $0.54 \mathrm{MHz}$ and $6 \mathrm{~W}$. This represented five of the seven subjects, and cough strength was strong (a score of 4 in all except one subject, in which cough strength was weak). Three of the seven coughed when stimulated bilaterally at $0.58 \mathrm{MHz}$ and $6 \mathrm{~W}$. Three of the five subjects $(60 \%)$ who responded with a cough did so on retesting at $0.54 \mathrm{MHz}$ and $9 \mathrm{~W}$. Comparison of the slope of the Respitrace curve recorded during the cough and a PEFR effort was not possible due to the unable to cough subjects being unable to follow commands.

\section{Cough Strength Validation Study}

We elicited a cough at the first application in all subjects. Figure 3 shows the PEFR for a maximum cough effort, stimulated cough, and rating of cough strength. These data are compared in Figure 3, with the 160 to $270 \mathrm{~L} / \mathrm{min}$ flow rate considered the lowest threshold for a cough effective in clearing secretions [18]. The PEFR of the stimulated coughs achieved $>90$ percent of maximum voluntary cough effort in the three subjects with a cough strength rating of 4 . Subjects 1 and 2 each coughed with a rated strength of 3 and achieved PEFR 80 and 61 percent 
Table 2.

Cough response to ultrasound stimuli: subjective data and Respitrace (respiratory induction plethysmography) analysis.

\begin{tabular}{|c|c|c|c|c|c|c|c|c|}
\hline Stimulus & $\begin{array}{c}\text { Power } \\
\text { (W) }\end{array}$ & $\begin{array}{l}\text { Frequency } \\
\text { (MHz) }\end{array}$ & $\% \mathrm{SC} \geq 2^{*}$ & $\begin{array}{c}\text { Sensation }^{\dagger} \\
(\text { mean } \pm \text { SD) }\end{array}$ & $\begin{array}{c}\text { Displacement }^{\ddagger} \\
(\text { mean } \pm \text { SD })\end{array}$ & $\begin{array}{c}\text { \%Displacement/ } \\
\text { QB Displacement }{ }^{\S}\end{array}$ & $\begin{array}{c}\operatorname{Max} S^{q} \\
(\operatorname{mean} \pm S D)\end{array}$ & $\begin{array}{c}\text { \%Max SL/ } \\
\text { PEFR Max } \\
\text { SL }^{* *}\end{array}$ \\
\hline Unilateral & 6 & 0.54 & 67 & $2.7 \pm 0.8$ & $79.6 \pm 18.9$ & 197.0 & $469.3 \pm 270.0$ & 71.4 \\
\hline Unilateral & 6 & 0.61 & 47 & $1.5 \pm 0.6$ & $77.3 \pm 17.5$ & 191.3 & $417.4 \pm 310.0$ & 63.5 \\
\hline Unilateral & 6 & 0.74 & 40 & $1.8 \pm 1.5$ & $79.2 \pm 23.8$ & 196.0 & $279.3 \pm 229.0$ & 42.5 \\
\hline Unilateral & 6 & 1.18 & 13 & $0.3 \pm 0.7$ & $72.5 \pm 19.8$ & 179.5 & $166.1 \pm 224.0$ & 25.3 \\
\hline Unilateral & 6 & 1.35 & 7 & $0.3 \pm 0.6$ & $59.8 \pm 50.3$ & 148.0 & $166.1 \pm 187.0$ & 25.3 \\
\hline Unilateral & 9 & 0.54 & 73 & $3.1 \pm 0.7$ & $97.1 \pm 29.5$ & 240.3 & $573.5 \pm 372.0$ & 87.2 \\
\hline Unilateral & 9 & 0.58 & 80 & $2.3 \pm 0.7$ & $93.0 \pm 28.7$ & 230.2 & $701.9 \pm 484.0$ & 106.8 \\
\hline Unilateral & 9 & 0.61 & 47 & $2.1 \pm 1.4$ & $76.7 \pm 23.8$ & 189.8 & $420.6 \pm 370.0$ & 64.0 \\
\hline Unilateral & 9 & 1.18 & 33 & $1.2 \pm 1.5$ & $72.2 \pm 31.5$ & 178.7 & $281.9 \pm 208.0$ & 42.9 \\
\hline Unilateral & 9 & 1.35 & 13 & $0.9 \pm 0.8$ & $83.4 \pm 38.3$ & 206.4 & $174.4 \pm 244.0$ & 26.5 \\
\hline Bilateral & 4 & 0.58 & 54 & $1.2 \pm 0.4$ & $100.5 \pm 28.8$ & 248.7 & $454.1 \pm 341.0$ & 69.1 \\
\hline Bilateral & 6 & 0.58 & 75 & $1.7 \pm 0.3$ & $99.4 \pm 34.3$ & 246.0 & $590.4 \pm 346.0$ & 89.8 \\
\hline \multicolumn{5}{|c|}{ Peak Expiratory Flow Rate } & $109.9 \pm 56.8$ & 272.0 & $657.5 \pm 404.0$ & 100.0 \\
\hline \multicolumn{5}{|c|}{ Quick Breathing } & $40.4 \pm 27.6$ & - & $139.7 \pm 79.5$ & - \\
\hline $\begin{array}{l}{ }^{*} \text { Percentage of su } \\
{ }^{\dagger} \text { Subjective data. } \\
{ }^{\ddagger} \text { Maximum displ } \\
{ }^{\S} \text { Representation } \\
{ }^{\natural} \text { Maximum slope } \\
{ }^{* *} \text { Representation } \\
\text { Max = maximum }\end{array}$ & $\begin{array}{l}\text { ects who cc } \\
\text { lepth of res } \\
\text { Respitrace } \\
\text { cough stre }\end{array}$ & $\begin{array}{l}\text { oughed at streng } \\
\text { espitrace curve, } \\
\text { spiration compar } \\
\text { e curve, giving s } \\
\text { ngth compared }\end{array}$ & $\begin{array}{l}\text { th level of } \geq 2 \text {, } \\
\text { giving semiqu } \\
\text { red with QB. } \\
\text { emiquantitativ } \\
\text { with PEFR. }\end{array}$ & $\begin{array}{l}\text { subjective data. } \\
\text { antitative represent } \\
\text { e representation of }\end{array}$ & $\begin{array}{l}\text { ation of depth of resp } \\
\text { force of cough. }\end{array}$ & piration. & 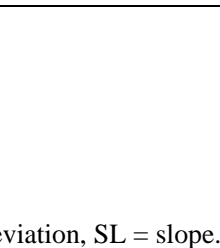 & 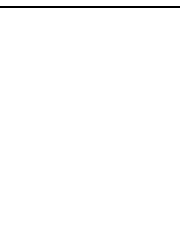 \\
\hline
\end{tabular}

of maximum, respectively. There was no significant difference between the maximum voluntary cough and the stimulated cough $(p=0.09)$ where the mean \pm standard deviations were $422.0 \pm 72.2$ and $354.0 \pm 74.0 \mathrm{~L} / \mathrm{min}$, respectively.

\section{DISCUSSION}

We achieved all aims of the clinical trials to test this new apparatus. The prototype CoughStim device is regularly able to safely stimulate a moderately strong cough without undue discomfort in nondisabled adults, including 80 percent at a specific frequency and power condition of $0.58 \mathrm{MHz}$ and $9 \mathrm{~W}$. Five out of seven subjects who were unable to cough responded with a cough from stimulation of $0.54 \mathrm{MHz}$ and $6 \mathrm{~W}$. The most effective parameter combinations for stimulating a cough for both subject groups were achieved with bilateral stimulation at 0.58 or $0.54 \mathrm{MHz}$ and $6 \mathrm{~W}$. The quality of the cough these parameters facilitated was usually normal or strong, thus of a sufficient volume for secretion removal. The sensory stimulus was moderate and so quite tolerable for all subjects. No adverse reactions to blood pressure, pulse rate, respiratory rate, $\mathrm{PEFR}$, or $\mathrm{SpO}_{2}$ occurred. We detected no symptoms of laryngeal spasm either during or after the testing procedure, and no subjects experienced any latent symptoms of tracheal irritation.

The stimulation combination at $0.54 \mathrm{MHz}$ and $6 \mathrm{~W}$ was shown to elicit a cough with a rated strength of 3 or 4 in nondisabled subjects. Four of the five subjects achieved a PEFR $>80$ percent of their PEFR during a maximum voluntary cough, with the fifth subject achieving 61 percent of a maximum. This subject achieved a PEFR of $230 \mathrm{~L} / \mathrm{min}$, which is above the lower limit of the suggested 160 to $270 \mathrm{~L} / \mathrm{min}$ flow rate for an effective 


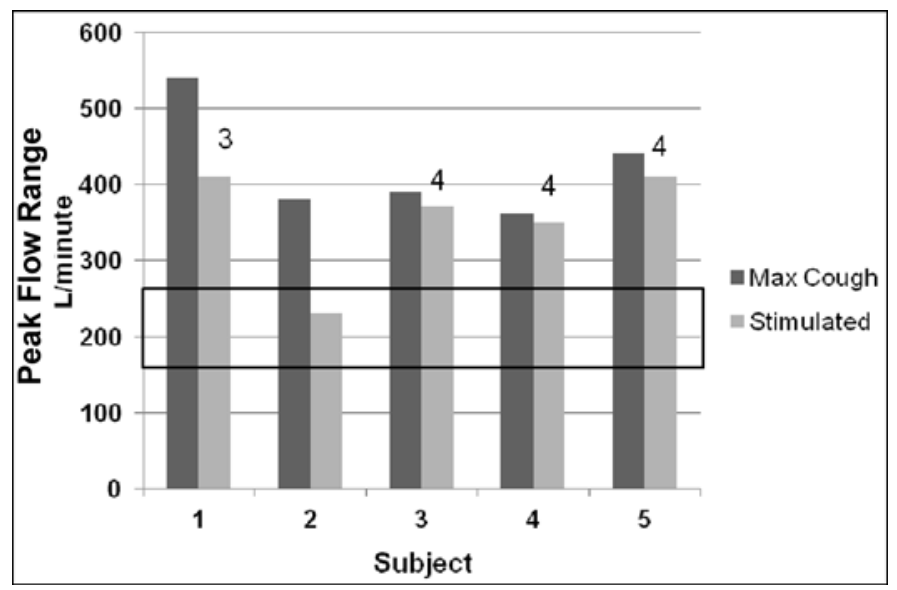

Figure 3.

Expiratory flow rate of maximum (max) voluntary cough compared with stimulated cough. Peak flow range above which cough is sufficient to clear secretions in humans indicated by box (160-270 L/min) [18].

cough. Furthermore, we found no statistical difference between stimulated and voluntary cough.

It is generally accepted that coughing is clinically important to clear mucosal secretions. Some subgroups of patients are physically unable to cough effectively, such as those with neuromuscular disease or spinal cord injuries. A device known as a mechanical in-exsufflator has been developed to assist these patients with lung clearance [22-23]. A device to elicit a cough in those who are cortically unable to respond to a request to do so, as opposed to physically unable to do so, would be similarly useful.

We compared the qualitative results from previously reported studies of methods of eliciting a cough using noninvasive mechanical vibratory stimulation with a modified men's shaver [11] or other methods including invasive electrostimulation of the trachea via an electrode inserted into the airway or stimulation by suction catheter [14] with the CoughStim prototype. The CoughStim results suggest this new equipment is a viable alternative or adjunct to current practice, namely using a suction catheter for clinical application. This claim is strengthened by our results that demonstrate the stimulated cough strength is achieving a flow rate known to remove secretions.

A number of comparisons need to be drawn between the results of this clinical trial and those of previous studies. When the results from the noninvasive mechanical vibration study on 15 nondisabled subjects were compared with the noninvasive CoughStim nondisabled sub- ject group, Lee and Eccles achieved 8 of 15 subjects responding with a cough compared with 100 percent of subjects responding with a cough when stimulated using the CoughStim prototype [11]. Further, the application time was considerably longer than our average of $3 \mathrm{~s}$ to achieve this result. On the other hand, Dekens et al. compared two invasive stimulatory methods of electro or mechanical (catheter) stimulation in ventilated patients with respiratory insufficiency [14]. They achieved a 100 percent responsive cough that was qualitatively considered to be normal to strong with electrostimulation and considered it as safe and effective as mechanical stimulation using a suction catheter.

Patient comfort must be considered during airway clearance using invasive or noninvasive methods since these techniques have to be applied at regular intervals in patients unable to clear their own airways to prevent airflow obstruction. Lee and Eccles did not report level of comfort but instead looked at perceived need to cough [11]. Dekens et al. considered comfort or perceived sensation during stimulation with the six conscious patients in the study feeling a mild tingling sensation during electrostimuluation [14]. Our nondisabled subject group perceived a moderate sensory level that was not uncomfortable and so acceptable. Only Dekens et al. compared effectiveness of sputum removal [14]. Their new method of cough stimulus had endotracheal suction, which is the usual method of secretion removal in patients unable to cough and expectorate unaided. Since removal of secretions is the aim of coughing, this measure should also be included in further trials of the CoughStim apparatus. Another similarity between Dekens et al. [14] and our study is that the patient groups contained those who were unable to cough efficiently to remove secretions. Therefore, these patients needed assistance to remove secretions, unlike the subjects in Lee and Eccles, who reported a recent upper respiratory tract infection and thus were more likely to have hyperreactive airways and so be more responsive to respiratory tract stimuli [11].

There are limitations to this preliminary report of the clinical trials of the CoughStim prototype. More studies are needed to show that the device can comfortably stimulate a strong cough in patients with other pathologies, such as acquired brain injury or postanesthetic, where guarding of the airways is deficient or the cough reflex diminished. We also need to measure volume of sputum removed with coughing stimulated by the CoughStim compared with endotracheal suctioning in these and other 
patient groups where assistance is required for airway clearance.

\section{CONCLUSIONS}

The CoughStim prototype has been shown to safely achieve a comfortable, strong cough in nondisabled subjects and a small group of older adults who were unable to cough on demand. The results likely suggest a broad capacity for patient application, particularly those with respiratory conditions where noninvasive secretion removal is important. The simplicity of application supports its introduction into practice.

\section{ACKNOWLEDGMENTS}

\section{Author Contributions:}

Study concept and design: J. C. Nitz, J. Perrier, P. Cook.

Acquisition of data: J. Perrier.

Analysis and interpretation of data: J. C. Nitz, P. Cook.

Critical revision of manuscript for important intellectual content:

P. Cook, J. Perrier, J. C. Nitz.

Administrative, technical, or material support: P. Cook, J. Perrier, J. C. Nitz.

Financial Disclosures: Mr. Perrier is the inventor and patent holder of the CoughStim device.

Funding/Support: This material was unfunded at the time of manuscript preparation.

Additional Contributions: Dr. Cook is now with Greenslopes Anaesthesia Services, Greenslopes, Brisbane, Australia.

Institutional Review: Ethical approval was obtained for studies 1 and 2 from the Medical Research Ethics Committee of The University of Queensland and Mater Health Services Human Research Ethics Committee and for study 3 from the Human Research Ethics Committee, Sisters of Charity \& Holy Spirit Health Service Queensland.

Participant Follow-Up: The authors plan to inform participants of the publication of this study.

\section{REFERENCES}

1. Jenkins S, Tucker B, Cecins N. Patients' problems, physiotherapy management and outcome measures. In: Pryor JA, Prasad SA, editors. Physiotherapy for respiratory and cardiac problems: Adults and paediatrics. Edinburgh (United Kingdom): Churchill Livingstone; 2008. p. 218-51.

2. Middleton S, Middleton PG. Assessment and investigation of patients' problems. In: Pryor JA, Prasad SA, editors. Physiotherapy for respiratory and cardiac problems: Adults and paediatrics. Edinburgh (United Kingdom): Churchill Livingstone; 2008. p. 1-20.

3. Smith Hammond CA, Goldstein LB, Zajac DJ, Gray L, Davenport PW, Bolser DC. Assessment of aspiration risk in stroke patients with quantification of voluntary cough. Neurology. 2001;56(4):502-6. [PMID:11222795] http://dx.doi.org/10.1212/WNL.56.4.502

4. Knowles MR, Boucher RC. Mucus clearance as a primary innate defense mechanism for mammalian airways. J Clin Invest. 2002;109(5):571-77. [PMID:11877463]

5. Addington WR, Stephens RE, Gilliland K, Rodriguez M. Assessing the laryngeal cough reflex and the risk of developing pneumonia after stroke. Arch Phys Med Rehabil. 1999;80(2):150-54. [PMID:10025488] http://dx.doi.org/10.1016/S0003-9993(99)90112-0

6. Ciesla ND. Chest physical therapy for patients in the intensive care unit. Phys Ther. 1996;76(6):609-25. [PMID:8650276]

7. Durbin CG Jr. Tracheostomy: why, when, and how? Respir Care. 2010;55(8):1056-68. [PMID:20667153]

8. Corke C, Cranswick P. A Seldinger technique for minitracheostomy insertion. Anaesth Intensive Care. 1988;16(2): 206-7. [PMID:3394915]

9. Irwin RS, Madison JM, Fraire AE. The cough reflex and its relation to gastroesophageal reflux. Am J Med. 2000; 108(Suppl 4a):73S-78S. [PMID:10718456] http://dx.doi.org/10.1016/S0002-9343(99)00341-1

10. Morice AH, Fontana GA, Belvisi MG, Birring SS, Chung KF, Dicpinigaitis PV, Kastelik JA, McGarvey LP, Smith JA, Tatar M, Widdicombe J; European Respiratory Society (ERS). ERS guidelines on the assessment of cough. Eur Respir J. 2007;29(6):1256-76. [PMID:17540788] http://dx.doi.org/10.1183/09031936.00101006

11. Lee P, Eccles R. Cough induced by mechanical stimulation of the upper airway in humans. Acta Otolaryngol. 2004; 124(6):720-25. [PMID:15515497] http://dx.doi.org/10.1080/00016480410017251

12. Wong $\mathrm{CH}$, Matai R, Morice AH. Cough induced by low pH. Respir Med. 1999;93(1):58-61. [PMID:10464850] http://dx.doi.org/10.1016/S0954-6111(99)90078-1

13. Lee PC, Eccles R. [Cough induction by high-frequency chest percussion in healthy volunteers and patients with common cold]. Respir Med. 2004;98(8):771-76.

[PMID:15303643]

http://dx.doi.org/10.1016/j.rmed.2004.01.006

14. Dekens JL, Mastboom WJ, Bultstra G, Oostveen E, Rasker JJ. Coughing reflex induced by electrostimulation of the trachea: a pilot study. Lancet. 1999;353(9156):902.

[PMID:10093993] http://dx.doi.org/10.1016/S0140-6736(99)00439-0

15. Stephens RE, Wendel KH, Addington WR. Anatomy of the internal branch of the superior laryngeal nerve. Clin Anat. 
JRRD, Volume 49, Number 9, 2012

1999;12(2):79-83. [PMID:10089032]

http://dx.doi.org/10.1002/(SICI)1098-

2353(1999)12:2<79::AID-CA1>3.0.CO;2-W

16. Widdicombe JG. Afferent receptors in the airways and cough. Respir Physiol. 1998;114(1):5-15.

[PMID:9858046]

http://dx.doi.org/10.1016/S0034-5687(98)00076-0

17. Low J, Reed A. Electrotherapy explained: Principles and practice. Oxford (United Kingdom): Butterworth-Heinemann; 1990.

18. Sancho J, Servera E, Díaz J, Marín J. Comparison of peak cough flows measured by pneumotachograph and a portable peak flow meter. Am J Phys Med Rehabil. 2004;83(8): 608-12. [PMID:15277962] http://dx.doi.org/10.1097/01.PHM.0000133431.70907.A2

19. Shah MD, Shah SM. The applied physiology of cough. Indian J Pediatr. 2001;68(SS2 Suppl 2):S3-10. [PMID:11411375]

20. Verschakelen JA, Demedts MG. Normal thoracoabdominal motions. Influence of sex, age, posture, and breath size. Am J Respir Crit Care Med. 1995;151(2 Pt 1):399-405. [PMID:7842198]

21. Grant S, Aitchison T, Henderson E, Christie J, Zare S, McMurray J, Dargie H. A comparison of the reproducibility and the sensitivity to change of visual analogue scales, Borg scales, and Likert scales in normal subjects during submaximal exercise. Chest. 1999;116(5):1208-17.

[PMID:10559077]

http://dx.doi.org/10.1378/chest.116.5.1208
22. Chatwin M, Ross E, Hart N, Nickol AH, Polkey MI, Simonds AK. Cough augmentation with mechanical insufflation/exsufflation in patients with neuromuscular weakness. Eur Respir J. 2003;21(3):502-8. [PMID:12662009] http://dx.doi.org/10.1183/09031936.03.00048102

23. Winck JC, Gonçalves MR, Lourenço C, Viana P, Almeida J, Bach JR. Effects of mechanical insufflation-exsufflation on respiratory parameters for patients with chronic airway secretion encumbrance. Chest. 2004;126(3):774-80.

[PMID:15364756]

http://dx.doi.org/10.1378/chest.126.3.774

Submitted for publication July 10, 2011. Accepted in revised form March 1, 2012.

This article and any supplementary material should be cited as follows:

Nitz JC, Perrier J, Cook P. In-vivo trial results of a novel ultrasonic cough stimulator. J Rehabil Res Dev. 2012; 49(9):1421-30.

http://dx.doi.org/10.1682/JRRD.2011.07.0121

ResearcherID: Jennifer C. Nitz, PhD, MPhty, BPhty: F-8745-2010; Peter Cook, MBBS, FANZCA, FCICM: F-4053-2012

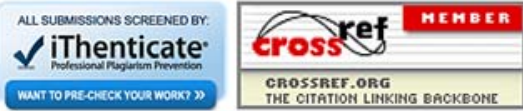

